УДК 504.03

ОСОБЕННОСТИ СОЦИАЛЬНОЙ ЭКОЛОГИЧЕСКОЙ РЕКЛАМЫ КАК МЕХАНИЗМА ФОРМИРОВАНИЯ ЭКОЛОГИЧЕСКОЙ КУЛЬТУРЫ НАСЕЛЕНИЯ

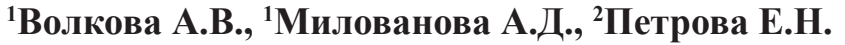 \\ ${ }^{1}$ ФГБОУ ВО «Нижегородский государственный педагогический университет \\ имени К. Минина», Нижний Новгород, е-mail:repulenko@mail.ru; \\ ${ }^{2}$ ФГБОУ ВО «Нижегородский государственный архитектурно-строительный университет», \\ Нижний Новгород, e-mail: petrova-e1@yandex.ru
}

В статье рассмотрены основные особенности социальной экологической рекламы, изучено ее влияние на формирование экологической культуры населения. Показана важная роль экологической рекламы в привлечении населения к геоэкологическим проблемам, среди которых потепление климата, утилизация отходов, исчерпание природных ресурсов, перепотребление. Среди особенностей нами выявлены ориентация на все общество в целом, общедоступность для разных социальных групп, эмоциональность, направленность на осмысление поведенческих особенностей во взаимоотношениях с окружающей средой. При современном уровне развития Интернета для использования экологической рекламы появились новые возможности. Особенно успешно экологическая реклама задействована социальными группами, такая информация находит отклик не только у профессионалов. Экологическая информация в социальных группах популярна благодаря коммуникативным свойствам социальных групп, возможности непосредственного участия в дискуссиях, а также простому, популяризированному преподнесению информации, в отличие от профессиональных лекций и специфической литературы. Для ситуации, сложившейся в нашей стране с корреляцией законодательной и исполнительной власти, иногда только экологическая культура населения может повлиять на качество окружающей среды. Для ее формирования применяются много ресурсов, среди которых экологическая реклама. Об успешности и эффективности формирования экологической культуры можно судить по увеличивающемуся числу подписчиков социальных сетей, возрастающему количеству людей, посещающих экологические акции, сортирующих вторичное сырье. В статье также сделано предположение, что социальная экологическая реклама используется преимущественно общественными экологическими организациями, государство же, по мнению авторов статьи, применяет некоммерческую рекламу недостаточно, отводя экологической социальной рекламе при этом совсем небольшую роль. Для улучшения качества окружающей среды такую ситуацию необходимо исправить.

Ключевые слова: социальная экологическая реклама, геоэкологические проблемы, качество окружающей среды, социальная группа, экологическая культура

\title{
FEATURE OF SOCIAL ECOLOGICAL ADVERTISING AS A MECHANISM FOR FORMING ECOLOGICAL CULTURE OF POPULATION
}

${ }^{1}$ Volkova A.V., ${ }^{1}$ Milovanova A.D., ${ }^{2}$ Petrova E.N.

${ }^{1}$ Kozma Minin Nizhny Novgorod State Pedagogical University, Nizhny Novgorod, e-mail: repulenko@mail.ru;

${ }^{2}$ Nizhny Novgorod State University of Architecture and Civil Engineering, Nizhny Novgorod, e-mail: petrova-e1@yandex.ru

The article considers the main features of social environmental advertising, the influence on the formation of the ecological culture of the population is studied. The article shows the important role of environmental advertising in attracting people to geo-environmental problems, including climate warming, waste management, exhaustion of natural resources, and overconsumption. Among the features we have identified orientation to the whole society as a whole, general accessibility for different social groups, emotionality, focus on understanding behavioral characteristics in relationships with the environment. With the current level of development of the Internet, new opportunities have appeared for using environmental advertising. Especially successfully environmental advertising is involved in social groups, such information is echoed not only by professionals. Environmental information in social groups is popular due to the communicative properties of social groups, the possibility of direct participation in discussions, as well as the simple, popularized presentation of information, in contrast to professional lectures and specific literature. For the situation in our country with the correlation of legislative and executive powers, sometimes only the ecological culture of the population can affect the quality of the environment. For its formation, many resources are used, including environmental advertising. Its success and the effectiveness of the formation of environmental culture can be judged by the increasing number of subscribers to social networks, the increasing number of people attending environmental events, sorting secondary raw materials. The article also suggests that social environmental advertising is used primarily by public environmental organizations, while the state, according to the authors of the article, does not use non-commercial advertising enough, assigning a very small role to environmental social advertising. To improve the quality of the environment, this situation needs to be fixed.

Keywords: social environmental advertising, geoecological problems, environmental quality, social group, environmental culture

На современную экологическую ситуацию в мире оказывает влияние множество факторов, среди которых особое значение имеет экологическая культура населения. От уровня ее сформированности зависит эмоционально-ценностное отношение 
к окружающей среде, в основе которого лежат экосообразные действия в интересах настоящего и будущих поколений.

Для формирования экологической культуры населения существуют разнообразные методы, среди которых система экологического образования на разных уровнях, система экологического законодательства в стране, экологическая политика государства, социальные мероприятия, проводимые экологическими общественными организациями, использование социальной экологической рекламы. Экологические организации применяют социальную рекламу для привлечения внимания населения к ряду геоэкологических проблем различного масштаба. Кроме того, экологическая социальная реклама может способствовать становлению экологического мышления, формированию коэволюционного мировоззрения.

Цель исследования заключается в изучении особенностей экологической рекламы как механизма повышения уровня экологических знаний у населения по основным геоэкологическим проблемам.

\section{Материалы и методы исследования}

Среди методов исследования особое внимание уделяется сравнительному, исследовательскому, описательному, аналитическому методам. Материалами для исследования послужили опубликованные исследования Федеральной службы государственной статистики, опубликованные отчеты некоммерческих экологических организаций, опубликованные рекламные проекты мировых, российских, региональных общественных экологических организаций.

\section{Результаты исследования и их обсуждение}

Общественная реклама представляется одним из видов некоммерческой рекламы. Информация в ней направлена на пробуждение различного рода эмоций в человеке, на привлечение внимания к локальным или региональным экологическим ситуациям, на популяризацию научных данных о глобальных геоэкологических проблемах.

Социальная экологическая реклама отличается от всех коммерческих видов рекламы тем, что не связана с продажами товаров или услуг, а направлена на информирование общества о каких-либо проблемах. Часто экологическая реклама обращается к образу семьи, поскольку семейные традиции это вечные ценности, принимаемые боль- шинством различных социальных групп населения. Коммерческая реклама нацелена на продажу товара, где обращение к семейным ценностям и искренним эмоциям имеет манипулирующую функцию, вызывает интерес к товару, доверие, а следовательно, пробуждает желание приобрести этот товар, что в конечном итоге увеличивает прибыль компаний. Социальная экологическая реклама тоже отчасти манипулирует подобными образами, но не в корыстных целях, в отличие от бизнеса, а для привлечения внимания населения, усиления психологического эффекта, осмысления своих действий, направленных на взаимоотношение с окружающей средой [1].

В настоящее время многие задумываются о качестве окружающей среды, геоэкологических проблемах. Вследствие процессов глобализации и ускоряющихся темпов технологического развития меняется облик нашей планеты. Быстрыми темпами возрастает антропогенная нагрузка на биосферу, приводя к серьезным последствиям, среди которых - деградация состояния окружающей среды и неблагоприятные изменения в общественной жизни [2]. Человечество не может существовать без природных благ, необходимых для его жизнедеятельности. Постоянно возрастающие темпы потребительского отношения к природе превосходят ее возможности самовосстановления.

Жесткая политика государства, взаимодействие законодательной и исполнительной власти, крупные штрафы приводят к улучшению качества окружающей среды, подтверждающим примером этого является государство Сингапур. В России подобная практика пока не применяется. В сложившейся ситуации наиболее продуктивным является формирование экологической культуры, с помощью только экономических мер и государственного регулирования справиться с экологическим кризисом довольно сложно. При сформированности экологически обдуманного поведения у населения необходимость жестких штрафов заметно снижается.

С распространением технического прогресса у человечества возникла возможность распространять информацию посредством мировой сети Интернет из любой точки планеты, находясь на территории любого государства, несмотря на уровень его социально-экономического развития. Это позволило намного быстрее вносить любую информацию в массы и получать от пользователей обратную связь. В своей 
статье «Модульная социальная экологическая реклама в сети Интернет» исследователь Н.А. Гудзь отмечает потенциальные возможности Интернета, которые значительно больше, чем у других способов передачи информации. Это происходит благодаря интерактивным свойствам, гибкости и глобальности распространения [3]. Этот потенциал также подтверждается данными статистических исследований, в которых отмечается, что наиболее востребованным вариантом использования сети Интернет для россиян являются социальные сети, в которых свое время проводят $78 \%$ опрошенных [4]. Вследствие этого большее внимание в распространении социальной экологической рекламы стоит уделить социальным сетям. Они популярны у населения, обладают определенным влиянием на массы, пользователи в них могут не просто видеть полезную информацию, но и обмениваться мнением, общаться, участвовать в дискуссиях, пользуясь широкими коммуникационными возможностями.

Лидерами среди заказчиков экологической социальной рекламы являются международная экологическая ассоциация «Greenpeace» и международная общественная организация «Всемирный фонд дикой природы», разнообразие методов визуализации, форм и стратегий, продвижения своей рекламы которых не могут оставить без внимания не только общественность, но и эксперты в сфере экологического просвещения.
Авторами были проанализированы геоэкологические проблемы, к которым «Greenpeace» привлекает внимание населения, и способы преподнесения информации, которые при этом используются (табл. 1).

Проанализировав информацию, можно отметить, что для различных геоэкологических проблем представители «Greenpeace» выбирают определенные способы подачи информации, которые наиболее оптимальны, по их мнению, для восприятия населением. Так, самые жесткие, негативные образы используются для привлечения внимания к тем глобальным проблемам, которые вызваны прямым антропогенным воздействием, приводящим к быстрой гибели животных и растений. Среди них загрязнение Мирового океана, уничтожение тропических лесов. Экологические проблемы, имеющие отложенное действие, представляются в основном через футуристические модели будущего.

Изучив частоту упоминания различных геоэкологических проблем в рекламных проектах некоммерческой организации «Greenpeace», можно прийти к следующим выводам. Наиболее часто организация обращается к таким проблемам, как уменьшение биологического разнообразия, уничтожение тропических лесов, загрязнение Мирового океана, чуть реже - к проблемам глобального потепления климата и загрязнения атмосферного воздуха, к истощению природных ресурсов (рисунок).

\section{Таблица 1}

Анализ использования различных видов социальной рекламы организацией «Greenpeace» по наиболее важным геоэкологическим проблемам

\begin{tabular}{|l|l|}
\hline \multicolumn{1}{|c|}{ Геоэкологическая проблема } & \multicolumn{1}{|c|}{ Используемые средства и образы } \\
\hline Разрушение озонового слоя & $\begin{array}{l}\text { Информация о негативном воздействии аэрозолей на озоновый слой } \\
\text { представляется через ассоциативные образы }\end{array}$ \\
\hline Глобальное потепление & $\begin{array}{l}\text { При создании рекламных образов применяются негативные образы } \\
\text { антропогенного воздействия на окружающую среду, наиболее часто - } \\
\text { урбанизированных территорий и крупных промышленных объектов }\end{array}$ \\
\hline Загрязнение Мирового океана & $\begin{array}{l}\text { Особенностями рекламы являются обращения к чувствам населения, } \\
\text { в основном через негативные образы. Целью применения таких об- } \\
\text { разов служат сильные эмоции, способствующие изменению мировоз- } \\
\text { зрения и поведения }\end{array}$ \\
\hline $\begin{array}{l}\text { Уменьшение биологического раз- } \\
\text { нообразия }\end{array}$ & $\begin{array}{l}\text { Создается единый образ человека и живой природы для достижения } \\
\text { гармонии с ней, происходит обращение к истокам человечества }\end{array}$ \\
\hline Уничтожение тропических лесов & $\begin{array}{l}\text { Для привлечения внимания и объединения усилий общества по реше- } \\
\text { нию проблемы обезлесения часто используется обезличенное «мы». } \\
\text { Применяются жестокие образы для эмоциональной реакции населения }\end{array}$ \\
\hline Опустынивание & $\begin{array}{l}\text { Используются образы футуристических моделей мира с целью обра- } \\
\text { щения внимания на существующую проблему }\end{array}$ \\
\hline
\end{tabular}




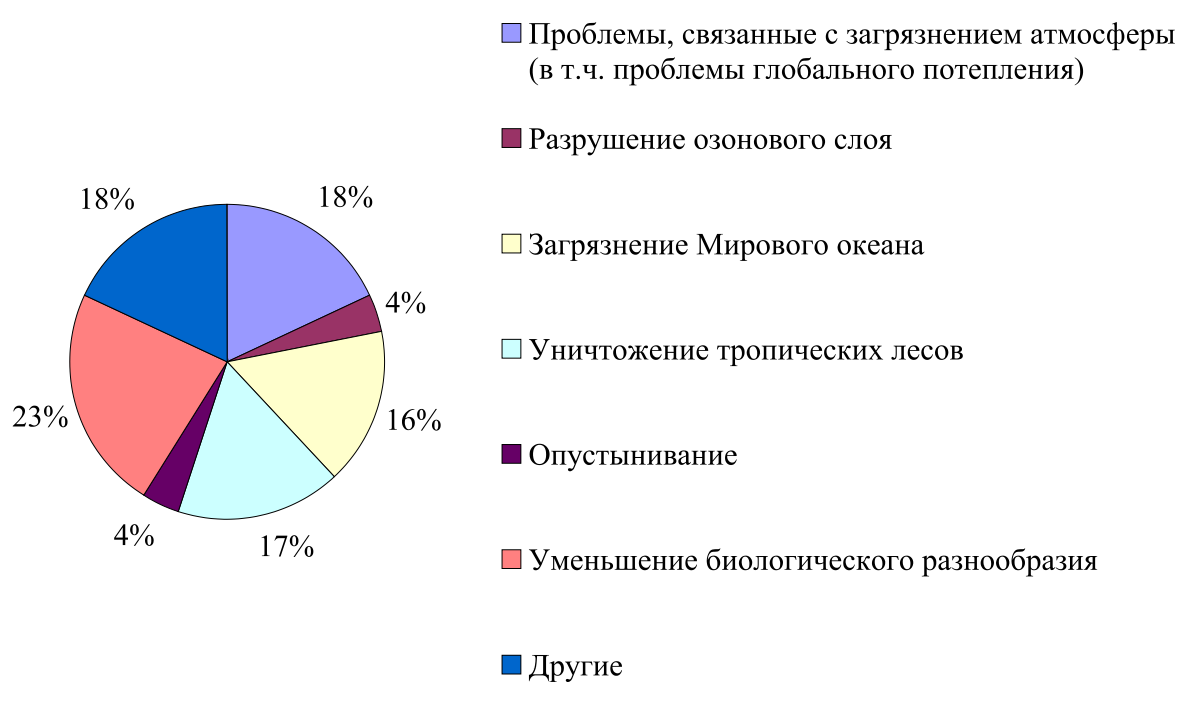

Соотношение различных видов геоэкологических проблем в общем количестве сочиальной рекламы «Greепреасе»

Значимой геоэкологической проблемой также является проблема утилизации и переработки отходов, которая оказывает большое влияние на многие сферы жизни общества и состояние экосистемы в целом. Помимо отторжения все больших территорий для складирования отходов, существует также опасность накопления парниковых газов, вызывающих потепление климата. Это глобальная геоэкологическая проблема, которая объединяет все государства для поиска путей решения. Один из эффективных способов решения - приобщение населения к экологической культуре.

Попытку решения проблемы утилизации отходов можно проиллюстрировать на примере Нижегородской области, где существует большое количество экологических общественных организаций, ведущих в социальных сетях свои коммуникационные страницы. Среди них «Изменим мир», «Нижний Новгород - экологическая столица», «РазДельно», «42 - я имею право!» и многие другие. У каждой группы своя специфика, но все они преимущественно направлены на повышение правовой грамотности населения, формирование навыков экологически обдуманного поведения, приобщение к раздельному сбору коммунальных отходов, отказу от перепотребления, решение глобальных геоэкологических проблем посредством гуманного отношения к окружающей среде.

Так, активисты движения экологической общественной организации «Изменим мир» посредством кампании «РазДельно» несколько лет пропагандируют эффективность раздельного сбора отходов для сохранения окружающей природной среды, привлекая население разных возрастных групп. Волонтеры организации проводят ежемесячные акции во всех районах г. Нижнего Новгорода и в других городах области по сбору вторичного сырья, напрямую сотрудничая с фирмами-переработчиками [5].

Для привлечения внимания аудитории к такой геоэкологической проблеме, как утилизация и переработка коммунальных отходов, используются следующие ресурсы: размещение материалов интервью с ведущими экологами области, проведение фестивалей документальных фильмов, акций по приему вторсырья, размещение социальной экологической рекламы.

Можно выделить несколько уровней эффективности экологической рекламы. На начальном уровне происходит привлечение внимания населения к проблеме, на последующем - принятие, усвоение информации. Максимальный эффект наблюдается при формировании новых убеждений, изменении общественного мнения по какому-либо явлению, процессу, экологической проблеме. Исследовать результативность влияния экологической рекламы на формирование экологической культуры довольно сложно. Это осуществляется специалистами на государственном уровне посредством различных аналитических исследований, при проведении которых необходимо учитывать множество факторов. 
Таблица 2

Итоги акций общественной организации «Изменим мир» по сбору вторичного сырья у населения в Нижегородской области (2019-2020 гг.)

\begin{tabular}{|l|c|c|c|c|}
\hline $\begin{array}{c}\text { Дата проведения } \\
\text { акции }\end{array}$ & $\begin{array}{c}\text { Количество точек } \\
\text { сдачи вторсырья }\end{array}$ & $\begin{array}{c}\text { Число добровольных } \\
\text { помощников (человек) }\end{array}$ & $\begin{array}{c}\text { Число участников } \\
\text { в акции (человек) }\end{array}$ & $\begin{array}{c}\text { Количество собран- } \\
\text { ного вторсырья (кг) }\end{array}$ \\
\hline Февраль 2019 г. & 8 & - & 985 & 2536 \\
\hline Апрель 2019 г. & 8 & - & 1010 & 2631,8 \\
\hline Август 2019 г. & 9 & - & 1163 & 4385,9 \\
\hline Сентябрь 2019 г. & 9 & - & 1056 & 3082,8 \\
\hline Октябрь 2019 г. & 9 & 72 & 1501 & 3621 \\
\hline Ноябрь 2019 г. & 10 & 119 & 1475 & 5216 \\
\hline Январь 2020 г. & 11 & 126 & 1523 & 4404,8 \\
\hline Февраль 2020 г. & 11 & 124 & 1455 & 4348,8 \\
\hline
\end{tabular}

В более узком смысле об эффективности экологической рекламы в социальных сетях Нижегородской области можно судить по постоянно увеличивающемуся количеству подписчиков, возрастающему числу участников акций «РазДельно» для сбора вторичного сырья, а также расширяющейся географии подобных акций по городам области, появлению новых сервисов по совместному потреблению и повторному использованию, увеличению популярности таких сервисов среди населения.

Так, например, в организации «РазДельно» ведется статистика изменений доли подписчиков. В апреле 2018 г. в их группе было 3000 подписчиков, в июле 2019 г. - 6000 человек, в мае 2020 г. - более 8000 граждан Нижегородской области. Ежегодное увеличение людей, состоящих в группе, заботящихся о состоянии окружающей среды, вызвано продуманной работой команды, успешной экологической рекламой.

Об успешности экологического просвещения также свидетельствуют статистические данные посещения акций по приему вторичного сырья (табл. 2).

Исходя из приведенных данных можно отметить, что происходит постоянное увеличение населения, участвующего в сдаче твердых коммунальных отходов для переработки, растет количество волонтеров. Так, при становлении проекта на каждой точке приема вторсырья было достаточно 3-4 человек, курирующих процесс приема, сейчас число волонтеров на некоторых пунктах достигает 18 человек. Продолжает увеличиваться и количество вторсырья, принесенного для переработки.

\section{Выводы}

В процессе создания проекта социальной рекламы важно учитывать множество факторов, среди которых - особенности восприятия рекламы разными группами населения, особенности менталитета жителей страны и иные, делать акцент на деталях с учетом анализа психологических установок, использовать методы убеждения и внушения. Наиболее эффективно социальная реклама воспринимается при использовании необычных форм и новых подходов к воздействию на подсознание.

Общественные экологические организации для привлечения внимания к экологическим проблемам все больше используют возможности социальных сетей, поскольку они обладают рядом функций, позволяющих оказывать наиболее сильное воздействие на население.

На современном этапе развития экологического просвещения назревает необходимость государственного содействия в создании и размещении экологической социальной рекламы, поскольку сейчас в ее формировании принимают участие только общественные экологические организации. При участии правительства от социальной рекламы можно было бы ожидать еще большего желаемого эффекта в сфере привлечения внимания к экологическим проблемам не только всего мира, но и к региональным, и местным локальным проблемам при участии регионального управления.

\section{Список литературы / References}

1. Помникова А.Ю. Семейная история в дискурсивном пространстве// Вестник Мининского университета. 2019. Т. 7. № 1. [Электронный ресурc]. URL: https:// 
vestnik.mininuniver.ru/jour/article/view/930 (дата обращения: 11.05.2020) DOI: 10.26795/2307-1281-2019-7-1-9.

Pomnikova A.Yu. Family stories in different types of discourse// Vestnik of Minin University. 2019. Vol. 7. № 1. [Electronic resource]. URL: https://vestnik.mininuniver.ru/ jour/article/view/930 (date of access: 11.05.2020) (in Russian).

2. Голубев Г.Н. Основы геоэкологии: учебник. 2-е изд. М.: Кнорус, 2013. 352 c.

Golubev G.N. Fundamentals of geoecology: a textbook. 2 ed. M.: Knorus, 2013. 352 p. (in Russian).

3. Гудзь Н.А. Модульная социальная экологическая реклама в сети Интернет // Universum: Филология и искусствоведение. 2014. № 2 (4). [Электронный ресурс]. URL: http://7universum.com/ru/philology/archive/item/1007 (дата обращения: 19.05.2020)

Gudz N.A. Modular social environmental advertising on the Internet// Universum: Philology and art history. 2014.

№ 2 (4). [Electronic resource]. URL: http://7universum.com/ ru/philology/archive/item/1007 (date of access: 19.05.2020) (in Russian).

4. Цифровая экономика: 2020: краткий статистический сборник. М.: НИУ ВШЭ, 2020. 112 с. [Электронный ресурс]. URL: https://issek.hse.ru/mirror/pubs/share/323871553 (дата обращения 11.05.2020).

Digital economy: 2020: a brief statistical compilation. M.: NRS HSE, 2020. 112 p. [Electronic resource]. URL: https:// issek.hse.ru/mirror/pubs/share/323871553 (date of access: 15.05.2020) (in Russian).

5. Волкова А.В., Копосова Н.Н. Устойчивое развитие городов Нижегородской области // Успехи современного естествознания. 2019. № 5. С. 42-46.

Volkova A.V., Koposova N.N. Sustainable development of cities of the Nizhny Novgorod region // Advances in current natural sciences. 2019.№ 5. P. 42-46 (in Russian). 